\title{
Primary Adrenal lymphoma presented with adrenal insufficiency
}

\author{
Evanthia Diamanti-Kandarakis ${ }^{1}$, Pantelis Chatzismalis ${ }^{1}$, Frangiskos Economou ${ }^{1}$, \\ Stefanos Lazarides ${ }^{1}$, Athena Androulaki ${ }^{2}$, Grigorios Kouraklis ${ }^{3}$
}

${ }^{1}$ Endocrine Section, First Department of Medicine, Athens University Medical School, ${ }^{2}$ Department of Pathology, Laiko General Hospital, ${ }^{3} 2^{\text {nd }}$ Department of Surgery Athens University Medical School, Athens, Greece

\begin{abstract}
We report a 71-year old man who presented with symptoms of adrenal insufficiency and large bilateral adrenal masses. Computed tomography guided FNA biopsy was not diagnostic. However, because of the rapid growth of the masses, the negative workup for primary malignancy and the strong clinical suspicion of a lymphoma, an open biopsy was performed and a B-cell lymphoma was disclosed.
\end{abstract}

Key words: Primary adrenal lymphoma

\section{INTRODUCTION}

Primary lymphoma of the adrenal gland is considered extremely rare ${ }^{1,2}$. A possible diagnosis of this entity should be suspected in cases presenting with a bilateral adrenal mass, with or without lymphadenopathy, and with or without affected endocrine function. Moreover, it should be differentiated from a possible metastatic disease involving both suprarenal glands and from other conditions affecting the adrenals such as congenital adrenal hyperplasia, bilateral pheochromocytoma, infections and traumatic hemorrhage.

This is a case of a patient with bilateral adrenal lymphoma, who presented with adrenal insufficiency and a rapidly growing retroperitoneal mass. The dif-

\footnotetext{
Address correspondence and requests for reprints to: Evanthia Diamanti-Kandarakis, Associate Professor of Medicine, Medical School University of Athens, Fax: +302108130031, e-mail: akandara@otenet.gr Received 29-09-03, Revised 26-10-03, Accepted 29-11-03
}

ficulties in establishing the diagnosis and the differential diagnosis of bilateral adrenal masses are discussed.

\section{CASE HISTORY}

The patient was a 71-year old man, in good health until 2 years previously when he started to feel pain in the lower thoracic and lumbar area. It was more often left sided, radiating to the left upper abdomen. The pain was vague, lasted for a few hours and could be satisfactorily relieved by non-steroidal anti-inflammatory drugs (NSAIDs). Progressively the pain intensity increased, appeared more frequently, lasted longer and became more resistant to over-the-counter analgesics. The obvious deterioration of the condition drove the patient to seek medical attention. The physical examination at that point was unremarkable except for an approximately $10 \mathrm{~kg}$ weight loss that the patient had not noticed. No other pathological findings or symptoms were reported such as fever, anore- 
xia, rash, pruritus, malaise or skin hyperpigmentation.

The patient continued to take NSAIDs for pain relief and later visited a surgeon since, by then, the pain was more frequently located in the lower abdomen. The pain was attributed to an inguinal hernia and the patient underwent an operation for hernia repair. Postoperatively, the patient's general health deteriorated with the patient complaining of anorexia, nausea, episodic vomiting and severe fatigue. Additionally, he had episodes of fainting while standing. Due to the dramatic change in the patient's condition, he was admitted to the local hospital for further investigation. The blood count and the biochemical parameters on the day of admission are shown in table 1 .

A computed tomography (CT) of the upper and lower abdomen was performed as part of the diagnostic workup and revealed a large mass on the left and a smaller one on the right adrenal glands (Figure
1). Based on the findings of hyponatremia, hyperkalemia and orthostatic hypotension in addition to the CT finding, the preliminary diagnosis of primary adrenal insufficiency was suggested. An MRI was performed to reveal two large, irregular and bilateral adrenal masses, sized $8 \mathrm{~cm}$ on the left and $4 \mathrm{~cm}$ on the right (Figure 2). Hydrocortisone replacement therapy appropriate to the patient's stress (100mg 3 times daily) was initiated and the patient's general condition improved rapidly. Fatigue, nausea, anorexia and vomiting subsided and the pain became more tolerable. The patient was then transferred to our department for further investigation and treatment.

On physical examination on admission, orthostatic hypotension was detected with supine blood pressure of $180 / 100 \mathrm{mmHg}$ and $72 \mathrm{bpm}$, and standing blood pressure $120 / 90 \mathrm{mmHg}$ and $120 \mathrm{bpm}$. No palpable mass was found in the abdomen and the patient was afebrile, and no skin hyperpigmentation was detected.

Table 1. Hematologic and biochemical data

\begin{tabular}{|c|c|c|c|c|}
\hline \multirow[b]{2}{*}{ Variable } & \multicolumn{2}{|c|}{ First hospital admission } & \multicolumn{2}{|c|}{ Admission to our Hospital } \\
\hline & $\begin{array}{l}\text { Before initiation } \\
\text { of hydrocortisone }\end{array}$ & $\begin{array}{l}\text { After initiation } \\
\text { of hydrocortisone }\end{array}$ & At presentation & Before open biopsy \\
\hline Erythrocyte Sedimentation Rate & $57 \mathrm{~mm}$ & & & \\
\hline CRP IU/L & & & & 107,14 \\
\hline Hematocrit (\%) & 38,4 & 34,1 & 32,5 & \\
\hline White cell count $/ \mu \mathrm{L}$ & 6200 & 9.350 & 3.800 & \\
\hline Platelets $/ \mu \mathrm{L}$ & 301.000 & 342.000 & 197.000 & \\
\hline Glucose mmol/L & 7,2 & & 7,44 & \\
\hline Urea $\mathrm{mmol} / \mathrm{L}$ & 18 & & 10,08 & \\
\hline Creatinine $\mu \mathrm{mol} / \mathrm{L}$ & 108,29 & & 74,97 & \\
\hline SGOT U/L & 42 & & 70 & \\
\hline SGPT U/L & 102 & & 37 & \\
\hline LDH U/L & 1817 & 530 & 4360 & 7112 \\
\hline CPK U/L & 172 & 25 & & \\
\hline ALP U/L & 100 & & 144 & \\
\hline GGT U/L & 72 & & 44 & \\
\hline Billirubin $\mu \mathrm{mol} / \mathrm{L}$ & 2,907 & & 8,721 & \\
\hline Serum amylase U/L & 135 & & 479 & \\
\hline Total proteins gr/L & $63 \mathrm{gr} / \mathrm{L}$ & & $57,7 \mathrm{gr} / \mathrm{L}$ & \\
\hline Albumin gr/L & $28 \mathrm{gr} / \mathrm{L}$ & & & \\
\hline $\mathrm{Na} \mathrm{mEq} / \mathrm{L}$ & 115 & 139 & 134 & \\
\hline $\mathrm{K} \mathrm{mEq} / \mathrm{L}$ & 5,25 & 4,3 & 4,1 & \\
\hline $\mathrm{Ca} \mathrm{mEq} / \mathrm{L}$ & & & 4,3 & \\
\hline Prothrombin time (sec) & & & $10,2(\mathrm{INR}=0,96)$ & \\
\hline
\end{tabular}




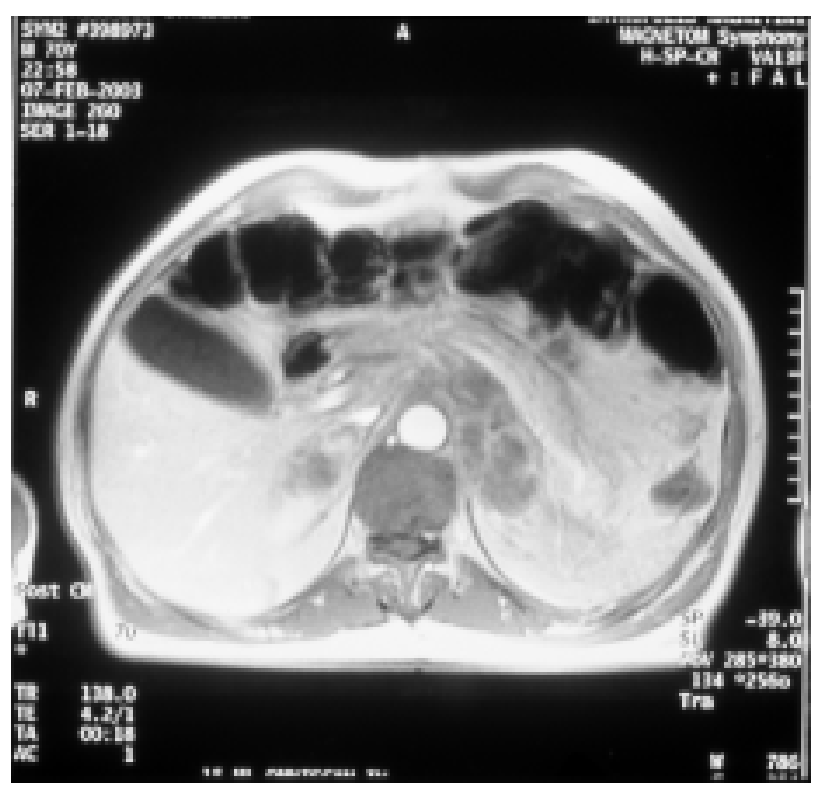

Figure 1. Computed tomography of the abdomen revealing a large mass on the left adrenal gland with marked heterogeneity due to cystic degeneration and a smaller mass on the right adrenal gland.

The blood count and biochemical parameters are shown in table 1 . The hormonal profile of adrenal function was diagnostic of primary adrenal insufficiency (Table 2).

Following these findings, a CT guided percutaneous needle biopsy was performed in order to determine the nature of the tumor. The examination of the specimen although not diagnostic, was suggestive of metastatic malignant carcinoma. The clinical picture, on the other hand, pointed towards a lymphoma. An open biopsy of the adrenal masses was decided.

While the patient was scheduled for the biopsy and was on hydrocortisone therapy, the symptoms resumed and fever was presented for the first time, up to $39^{\circ} \mathrm{C}$.

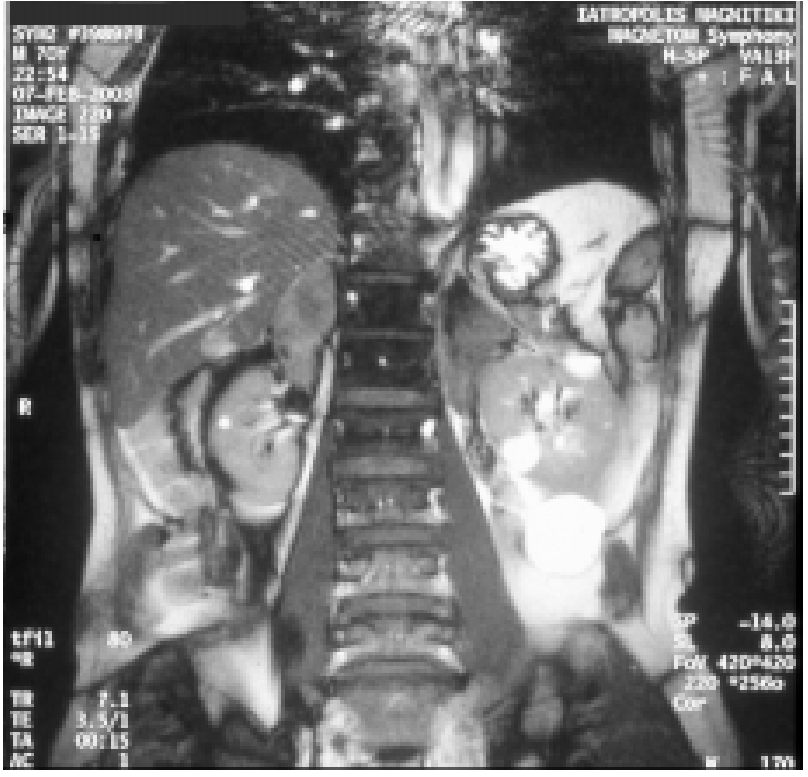

Figure 2. MRI of the abdomen demonstrating the infiltration of both adrenal glands. The mass on the left adrenal gland is extended from the kidney to the diaphragm.

At that time a urinary tract infection was suspected due to the finding of pyuria at a urine test and antibiotics were given without any response whatsoever. The physical examination at that stage revealed a large, hard, non-tender mass in the upper abdomen. A new CT scan was performed which showed a large, heterogeneous, retroperitoneal mass infiltrating both adrenal glands and the left kidney. During the following days, the patient's condition deteriorated rapidly and the abdominal mass continued to grow.

An open biopsy was performed to establish the diagnosis. Histology confirmed the clinical suspicion of lymphoma: large B cell anaplastic non-Hodgkin's lymphoma (Figure 3). The histological findings in the absence of any evidence of other tissue involvement

Table 2. Adrenal function assessment.

\begin{tabular}{lcc}
\hline Variable & Values detected & Reference values \\
\hline Urine & & \\
VMA mg/24 hours $(\mu \mathrm{mol} / 24 \mathrm{hrs})$ & $2,4(12,1)$ & $1,8-6,7(9,-33,8)$ \\
Metanephrines $\mathrm{mg} / 24 \mathrm{hrs}(\mu \mathrm{mol} / 24 \mathrm{hrs})$ & $0,3(1,6)$ & $<1(<5,5)$ \\
Blood: & & \\
Cortisol $\mu \mathrm{g} / \mathrm{dl}(\mathrm{nmol} / \mathrm{L})$ & $5,8(170)$ & $5,8-25(170-689)$ \\
ACTH $\mathrm{pg} / \mathrm{ml}$ & 125 & $9-52$ \\
Renin $\mu \mathrm{IU} / \mathrm{ml}$ & 8,0 & $5,0-47$ \\
Aldosterone ng/dl $(\mathrm{nmol} / \mathrm{L})$ & $2,0(0,055)$ & $1,0-16(0,027-0,44)$ \\
\hline
\end{tabular}



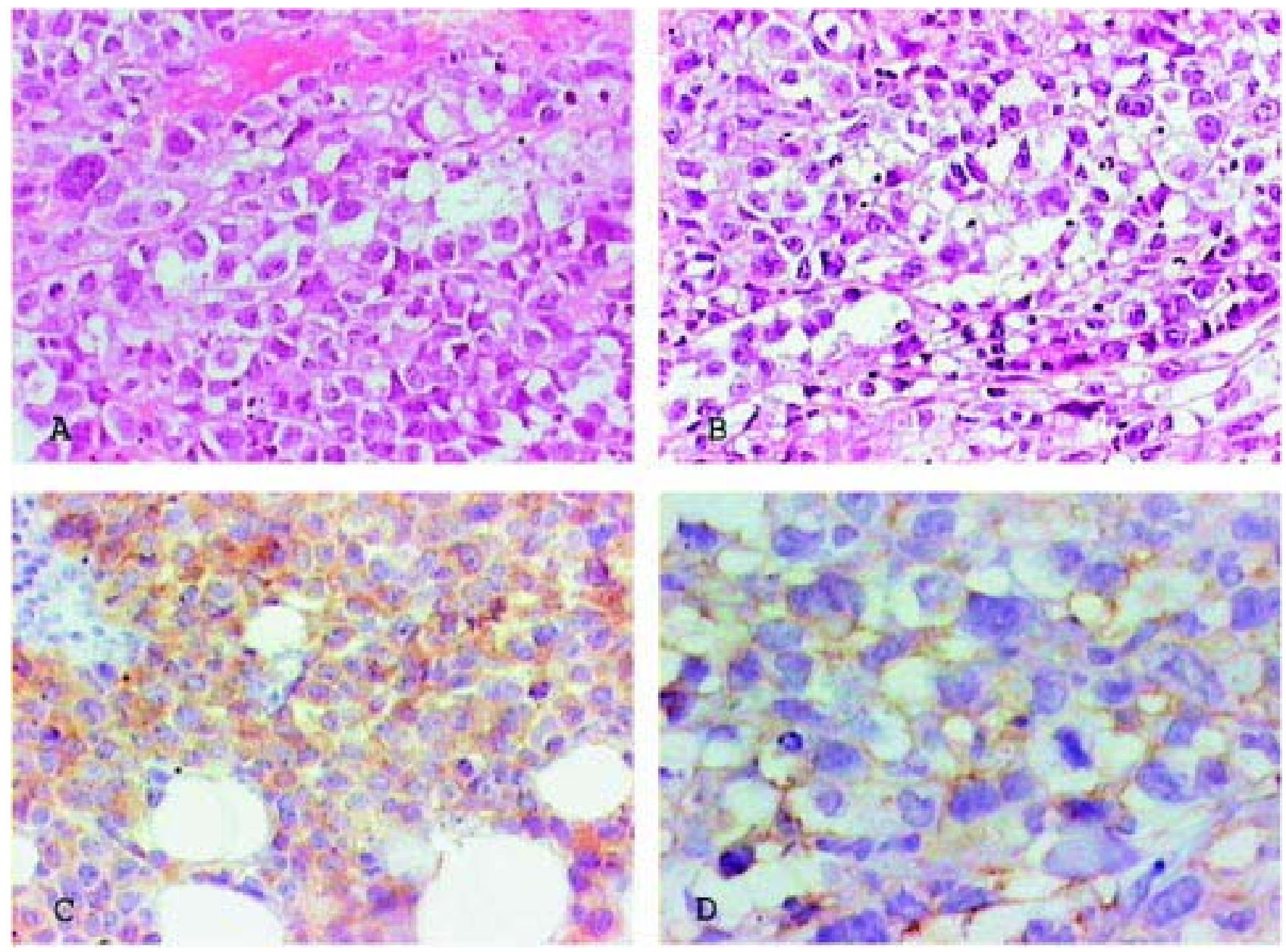

Figure 3. High grade B cell non-Hodgkin lymphoma (large cell type) with anaplastic morphology A, B: H\&E X400, C: L-26 X400, D: CD 30 X400 (L26 B cell lineage marker, CD 30 marker of activation in non-Hodgkin lymphomas).

with lymphoma, by computed topography scans of the head, neck, chest and abdomen, confirmed the diagnosis of a bilateral primary adrenal lymphoma (PAL). Before any further therapeutic intervention could take place, the patient passed away.

\section{DISCUSSION}

The patient was first admitted to the hospital with postural hypotension and hyponatremia. The combination of these findings is suggestive of hypovolemic hyponatremia, a condition seen in relatively few pathologies ${ }^{3}$. Taking into consideration the additional findings of hyperkalemia, fatigue, nausea and vomiting, the preliminary diagnosis points towards adrenal insufficiency. Although chronic primary adrenal insufficiency is commonly accompanied by skin pigmentation $^{4}$, the lack of this finding in this case could be explained by the rapid onset of the disease. According to the literature, increased skin pigmentation is present in 15 percent of PAL cases 5 .

The conditions associated with bilateral adrenal masses and adrenal insufficiency are listed in table $3^{15,21}$. Although pheochromocytoma is bilateral in $10 \%$ of cases and should be the first condition to be excluded, it is rarely associated with adrenal insufficiency. In this case, the normal urine values of VMA and metanephrines make the diagnosis of pheochromocytoma unlikely.

Cushing's disease or ectopic ACTH secretion (e.g. small cell lung carcinoma, carcinoid, and pheochromocytoma) can result in bilateral adrenal enlargement. Almost always, though, this enlargement ranges from small to moderate, and the clinical and laboratory findings of Cushing's syndrome are present, as opposed 
Table 3. Causes of bilateral adrenal masses.

\begin{tabular}{l} 
Malignant tumors \\
Metastatic \\
Lung carcinoma \\
Breast carcinoma \\
Renal malignant tumor \\
Melanoma \\
Gastrointestinal tract \\
Primary \\
Lymphoma \\
Pheochromocytoma \\
Adrenocortical carcinoma \\
Neuroblastoma \\
Endocrinopathy \\
ACTH-dependent Cushing's syndrome. \\
Macronodular adrenal hyperplasia \\
Congenital adrenal hyperplasia \\
Benign pheochromocytoma \\
Infections \\
Tuberculosis \\
Fungal infections \\
Histoplasmosis \\
Blastomycosis \\
Cryptococcosis \\
Ancidentaloma \\
Amyloidosis \\
\hline
\end{tabular}

to those of adrenal insufficiency reported in the present case.

Congenital adrenal hyperplasia, another condition that causes enlargement of adrenals, is usually presented in childhood ${ }^{6,7}$.

Primary endocrine lymphomas are rare clinical entities accounting for less than $3 \%$ of extranodal lymphomas $^{8}$ and most of them involve the thyroid gland. In particular, primary adrenal lymphoma is an extremely rare condition with fewer than a hundred cases reported worldwide (83 cases up to April 2003) ${ }^{9}$, as opposed to secondary adrenal lymphomas which occur in about $25 \%$ of cases of B-cell lymphoma on post- mortem examination ${ }^{10}$. They usually present with bilateral adrenal masses (73\%) with moderate to severe adrenal enlargement (sizes ranging from 3 to 17 $\mathrm{cm})^{5,9}$. There is a male to female ratio of about 2.2-7: 1 and the mean age of appearance is 68 years 5 .

Additionally to the classical clinical symptomatology of lymphomas, the clinical picture of adrenal insufficiency may predominate or precede the other manifestations ${ }^{11}$. Patients present with fever, weight loss, abdominal pain and the symptoms of primary adrenal insufficiency fatigue, nausea, vomiting, anorexia and orthostatic hypotension ${ }^{5,11}$. Very often a firm, nontender mass is palpable on abdominal examination".

More than 90 percent of the adrenal tissue must be destroyed before adrenal insufficiency occurs ${ }^{11,22}$. This is the reason that, although adrenal metastases from solid tumors are common, they rarely manifest adrenal insufficiency. However, a latent adrenal insufficiency demonstrated by an inadequate response to a cosyntropin stimulation test has been reported in 33 percent of the patients ${ }^{12}$.

On the other hand, clinically apparent adrenal insufficiency is reported in about two thirds of the patients with bilateral PAL and can be present even in cases with only mild enlargement of the adrenal glands ${ }^{1,2,13}$. The diffuse type of infiltration, and the complete destruction of the architecture of the adrenal glands by the lymphoma may be responsible for the increased incidence of adrenal insufficiency in PAL cases.

PAL usually appears on CT as a heterogeneous mass with areas of cystic degeneration due to necrosis or hemorrhage ${ }^{5,14}$, in contrast to secondary adrenal lymphomas that usually appear as homogeneous solid masses.

Image guided FNA biopsy of the adrenal is the procedure of choice to establish the diagnosis ${ }^{5,13}$, although it may sometimes be non-diagnostic due to necrotic areas, as was the case in this patient ${ }^{15}$.

Histologically, $90 \%$ of primary adrenal lymphomas are of B-cells, usually large, that diffusely infiltrate the tissue $\mathrm{e}^{5,13,16}$.

Chemotherapy, surgery and radiation have been used in the treatment of PAL with poor results ${ }^{13}$. Radiation seems to be ineffective in these $\operatorname{cases}^{5,17}$. Chemotherapy (usually $\mathrm{CHOP}^{18}$ ) has occasionally resulted 
in temporary remission of the disease. Surgical removal before chemotherapy reduces the bulk of the mass ${ }^{19}$. On the other hand, chemotherapy when used preoperatively decreases tumor size, reduces hemorrhage and increases the efficacy of surgical approach. However there is no conclusive evidence that any of these combinations alter the outcome or the prognosis of the patients with $\mathrm{PAL}^{13}$. Irrespective of the treatment modality used, prognosis is very poor and more than 90 percent of the patients die within one year after the diagnosis ${ }^{5,9,20}$. Poor prognostic factors are advanced age, large tumors, the presence of adrenal insufficiency and high levels of lactate dehydrogenase. Early diagnosis is very hard to make because of the absence of any pathognomonic symptoms or signs of the disease and is usually established in advanced stages.

\section{REFERENCES}

1. Choi CH, Dusishin M, Garbadawala ST, Richard J, 1990 Non-Hodgkin's lymphoma of the adrenal gland. Arch Pathol Lab Med 114: 883-885.

2. Bauduer F, Delmer A, Le Tourneau A, et al, 1992 Primary adrenal lymphoma. Acta Haematol 88: 213-215.

3. Adrogue JH, Madias EN, 2000 Hyponatremia. N Engl J Med 342: 1581-1589

4. Stewart MP 2003 The adrenal cortex. In:Williams textbook of Endocrinology, Saudners, Philadelphia; p, 528.

5. Wang J, Sun NCJ, Renslo R, et al, 1998 Clinically silent primary adrenal lymphoma: a case report and review of the literature. Am J Hematol 58: 130-136.

6. Mokshagundam SP, Surks MI, 1993 Congenital adrenal hyperplasia diagnosed in a man during workup for bilateral adrenal masses. Arch Intern Med 153: 1389-1391.

7. Ravichandran R, Lafferty F, McGinniss MJ, Taylor HC, 1996 Congenital adrenal hyperplasia presenting as massive adrenal incidentalomas in the sixth decade of life: report of two patients with 21-hydroxylase deficiency. J Clin Endocrinol Metab 81: 1776-779.

8. Freeman C, Berg JW, Culter SJ, 1972 Occurrence and prognosis of extranodal lymphomas. Cancer 29: 252-260.
9. Axiang Xu, Xuren Xiao, Linyang YE, Baofa Hong, Xiaoxiong-Wang 2003 Primary adrenal lymphoma. Leuk Lymphoma 44: 739-740.

10. Rosemberg SA, Diamond HD, Jaslowitz B, Craver LF, 1961 Lymphosarcoma: a review of 1296 cases. Medicine 40: 31-84.

11. Huminer D, Garty M, Lapidot M, Leiba S, Borohov H, Rosenfeld JB, 1988 Lymphoma presenting with adrenal insufficiency: adrenal enlargement on computed tomographic scanning as a clue to diagnosis. Am J Med 84: 169-172

12. Redman BG, Pazdur R, Zingas AP, Loredo R, 1987 Prospective evaluation of adrenal insufficiency in patients with adrenal metastasis. Cancer 60: 103-107.

13. Hsu CW, Ho CL, Sheu WHH, Harn HJ, Chao TY, 1999 Adrenal insufficiency caused by primary aggressive nonHodgkin's lymphoma of bilateral adrenal glands: report of a case and literature review. Ann Hematol 58: 130-136.

14. Alvarez-Castells A, Oedraza S, Tallada N, Castella E, Gifre L, Torrents C, 1993 CT of primary bilateral adrenal lymphoma. J Comput Assist Tomogr 17: 408-409.

15. Case Records of the Massachusetts General Hospital, 2000 Weekly Clinicopathological Exercises. Case 35-2000. An 82-year old woman with bilateral adrenal masses and a low-grade fever. N Engl J Med 343: 1477-1483

16. Pimentel M, Johnston JB, Allan DR, Greenberg H, Bernstein CN, 1997 Primary adrenal lymphoma associated with adrenal insufficiency: a distinct clinical entity. Leuk Lymphoma 24: 363-367.

17. Sasagawa I, Sadamori N, Itoyama T, et al, 1995 Primary adrenal lymphoma with chromosomal abnormalities. Acta Haematol 94: 156-162.

18. Salvatore JR, Ross RS, 1999 Primary adrenal lymphoma. Leuk Lymphoma 34: 111-117.

19. Kuyama A, Takeuchi M, Munemasa M, et al, 2000 "Successful treatment of primary adrenal non-Hodgkin's lymphoma associated with adrenal insufficiency”. Leuk Lymphoma 38: 203-205.

20. Lee KS, Chung Ys, Park KH, Kim HS, Him HM, 1999 A Case of primary bilateral adrenal lymphoma with partial adrenal insufficiency. Yonsei Med J 40: 296-300.

21. Lopez E, Piedrola G, Villalon L, 1995 Bilateral adrenal masses. Postgrad Med J 71: 567-568.

22. Kung AW, Pun KK, Lam K, Wang C, Leung CY, 1990 Addisonian crisis as presenting feature in malignancies. Cancer 65: 177-179. 